\title{
Genotypic Variation in Nutritive and Bioactive Composition of Foxtail Millet
}

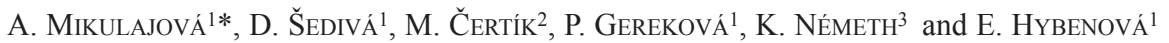 \\ ${ }^{1}$ Department of Nutrition and Food Quality Assessment, \\ ${ }^{2}$ Institute of Biotechnology, Faculty of Chemical and Food Technology, Slovak University of Technology, \\ Radlinského 9, Bratislava, 812 37, Slovak Republic \\ ${ }^{3}$ Food Research Institute, Priemyselná 4, Bratislava, 824 75, Slovak Republic
}

(Received 20 July 2016; Accepted 12 December 2016;

Communicated by R.K. Behl)

\begin{abstract}
Foxtail millet (Setaria italica) genotypes with red and yellow colour of grain bran were examined and compared for their content of nutritive components, fatty acids and phenolic compounds profile. Moreover, the antioxidant properties were investigated using three different methods. Foxtail millet genotypes contained $14.2 \%$ of protein, $5.0 \%$ of fat and $4.3 \%$ of soluble sugars, on average. Linoleic acid was the most abundant unsaturated fatty acid and palmitic acid was the most abundant saturated fatty acid. Four hydroxybenzoic acids (gallic, protocatechuic, vanillic and syringic acid) and two hydroxycinnamic acids (ferulic and $p$-coumaric acid) were identified and quantified. All genotypes exhibited effective inhibition of free radicals. Nevertheless, ferrous ion chelating activity was weak. Antioxidant properties of foxtail millet genotypes were closely associated with the presence of phenolics. A relationship between intensity of grain colour and antioxidant properties as well as phenolic compounds content, was observed. We can conclude that the content of evaluated parameters varied among foxtail millet genotypes, therefore their assessment and selection is desirable in order to cultivate crops and produce foods with advanced nutritional and antioxidant properties.
\end{abstract}

Keywords: foxtail millet, nutrient, fatty acids, phenolic compounds, antioxidant activity

\section{Introduction}

Cereals are important source of proteins, dietary fibre, lipids, minerals, vitamins and antioxidant active compounds in the human diet. Consumption of whole grain products is linked with reduced prevalence of diseases, such as cancer, type 2 diabetes, obesity, cardiovascular disease, hypertension (Chlopicka et al. 2012). These health benefits may be attributed to the antioxidant activity of cereal components (Zhang and Liu 2015).

Millets, as one of the oldest cereal grains, belong to the family Poaceae and various taxonomic genus. Millets are commonly grown in tropical and semiarid regions of Asia and Africa, where they are served as common staple foods (Chandrasekara et al. 2012). Traditional millet foods are pancakes, chapattis, porridges, couscous, beverages (Hegde 
and Chandra 2005; Chandrasekara et al. 2012). Millets have high nutritive quality, and contain substantial amounts of fat and proteins with remarkable essential amino acids content (Kamara et al. 2009). Additionally, millets are gluten-free, what is especially favourable attribute for people with celiac disease (Amadou et al. 2013). Foxtail millet originates from China, and now is worldwide produced. It is important and popular crop for its nutritional value and its ability to grow under adverse heat as well as limited rainfall conditions (Amadou et al. 2013). Epidemiological studies have shown that increased consumption of foxtail millet can reduce the risk of chronic diseases, such as metabolism of cholesterol, and type 2 diabetes (Zhang and Liu 2015).

To the best of our knowledge, there is no study focused on genotypic variation of compounds in different foxtail millet genotypes. Aim of our study was to offer the information about nutritional and biological active compounds contained in four foxtail millet genotypes differing in bran colour. The deviations in the biosynthesis stabilities of the compounds studied are also discussed.

\section{Materials and Methods}

\section{Materials and reagents}

Cereal samples of four foxtail millet genotypes (Setaria italica) with two different colour of bran, red genotypes $(00002,0011)$ and yellow genotypes (Slovenský, Friderica) were provided by the Gene bank of the Research Institute of Plant Production (Piešt'any, Slovak Republic). Crops were grown in locality Piešt'any (Slovak Republic) and harvested in 2010. Hexane (p.a.), ethyl acetate (p.a.), methanol (HPLC grade), acetonitrile (HPLC grade), acetic acid (p.a.), and chloroform (p.a.) were purchased from Mikrochem, Pezinok, Slovak Republic. The standards of C4-C24 fatty acid methylesters, heptadecanoic acid, 2,2-diphenyl-1-picrylhydrazyl (DPPH) radical, $\beta$-carotene, aluminium chloride, phenolic compounds standards were purchased from Sigma-Aldrich, Steinheim, Germany. Linoleic acid, Tween 20, ferrozine and Folin-Ciocalteu reagent were purchased from Merck, Darmstadt, Germany.

\section{Sample preparation}

The foxtail millet genotypes were milled and passed through a $0.5 \mathrm{~mm}$ mesh sieve. The fine flours were defatted with hexane (1:5, twice, $1 \mathrm{~h}$ at room temperature), and extracted with $65 \%$ ethanol $\left(1: 20\right.$, three times, $1 \mathrm{~h}$ at $\left.80^{\circ} \mathrm{C}\right)$. The extraction conditions were optimized based on experimental design method (Mikulajová et al. 2007). Ethanol was evaporated and the residues were extracted with ethyl acetate (1:1, twice), concentrated to dryness and dissolved in $96 \%$ ethanol for determination of antioxidant activities, total phenolic and total flavonoid content, and in methanol for phenolic compounds analysis by HPLC/DAD. For fatty acid analysis, milled grains $(1 \mathrm{~g})$ were extracted with $50 \mathrm{ml}$ chloroform/methanol (2:1, twice, $1 \mathrm{~h}$ at room temperature). The extracts were filtered, purified 
with water (1.20 multiple addition) and centrifuged for 10 minutes. The supernatants were dried and the residues were dissolved in hexane/chloroform $(9: 1)$.

\section{Proximate analysis}

The proximate composition of foxtail millet genotypes, including moisture, protein, fat, soluble sugars were determined according to ISO 11085:2008, ISO 20483:2006, ISO 712:2009 and STN 56 0512:1973.

\section{Fatty acid analysis}

Fatty acid profile was analysed by gas chromatography according to Čertík et al. (1996) after methylation. Gas chromatograph (GC-6890 N, Agilent Technologies, Santa Clara, California, USA) was equipped with FID detector (constant flow, hydrogen $40 \mathrm{ml} / \mathrm{min}$, air $\left.450 \mathrm{ml} / \mathrm{min}, 250^{\circ} \mathrm{C}\right)$ and DB-23 capillary column $(60 \mathrm{~m} \times 0.25 \mathrm{~mm}$, film thickness $0.25 \mu \mathrm{m}$, Agilent Technologies, Santa Clara, California, USA). The measurements were carried out under a temperature gradient $\left(150^{\circ} \mathrm{C}\right.$ held for $3 \mathrm{~min} ; 150-175^{\circ} \mathrm{C}$ at program rate $7.0^{\circ} \mathrm{C} / \mathrm{min} ; 175^{\circ} \mathrm{C}$ held for $5 \mathrm{~min} ; 175-195^{\circ} \mathrm{C}$ at program rate $5.0{ }^{\circ} \mathrm{C} / \mathrm{min} ; 195-$ $225^{\circ} \mathrm{C}$ at program rate $4.5^{\circ} \mathrm{C} / \mathrm{min} ; 225^{\circ} \mathrm{C}$ held for $0.5 \mathrm{~min} ; 225-215^{\circ} \mathrm{C}$ at program rate $10{ }^{\circ} \mathrm{C} / \mathrm{min} ; 215^{\circ} \mathrm{C}$ held for $7 \mathrm{~min} ; 215-240{ }^{\circ} \mathrm{C}$ at program rate $10{ }^{\circ} \mathrm{C} / \mathrm{min} ; 240{ }^{\circ} \mathrm{C}$ held for $7 \mathrm{~min}$ ) with hydrogen as a carrier gas (flow $2.5 \mathrm{ml} / \mathrm{min}$, velocity $57 \mathrm{~cm} / \mathrm{s}$, pressure 220 $\mathrm{kPa}$ ) and a split ratio of $1 / 20$ (inlets: heater $230{ }^{\circ} \mathrm{C}$; hydrogen flow $51 \mathrm{ml} / \mathrm{min}$ for $2 \mathrm{~min}$, then hydrogen flow $20 \mathrm{ml} / \mathrm{min}$; pressure $220 \mathrm{kPa}$ ). The fatty acid methylester peaks were identified according to the authentic standards of C4-C24 fatty acid methylesters mixture and quantified by an internal standard of heptadecanoic acid (C17:0). The fatty acid quantification was evaluated with ChemStation software 10.2. The index of fatty acid unsaturation IU $(\Delta / \mathrm{mol})$ was calculated by the following formula (Čertík and Shimizu 2000):

$$
\mathrm{IU}=[1(\Sigma \% \text { monoenes })+2(\Sigma \% \text { dienes })+3(\Sigma \% \text { trienes })] / 100
$$

\section{DPPH radical scavenging activity}

DPPH radical scavenging activity was examined in accordance with Yen and Chen (1995). The decrease in absorbance at $517 \mathrm{~nm}$ as result of DPPH radical decolouration from purple to yellow colour was determined. The standard curve was prepared by dilution of DPPH stock solution ( $\mathrm{c}=0.12 \mathrm{mg} / \mathrm{ml}$ in ethanol) and the total antioxidant capacity of tested sample was expressed as the amount of scavenged DPPH radicals per gram of foxtail millets dry weight (mg DPPH/g dw).

\section{$\beta$-carotene/linoleic acid bleaching method}

The decolouration of $\beta$-carotene was detected as described by Ismail et al. (2004). The measurement was carried out at intervals of 15 min for 120 min at $470 \mathrm{~nm}$ against a blank, consisting of an emulsion without $\beta$-carotene. Antioxidant activity was expressed as per- 
centage inhibition (\%) relative to the control (emulsion without foxtail millet extract) using the degradation rate parameter calculated according to the first-order kinetics (Makris and Rossiter 2001).

\section{Ferrous ion chelating activity}

The chelating activity of foxtail millet genotypes was estimated by the method of Gülçın et al. (2003). The decrease in absorbance at $562 \mathrm{~nm}$ was noted. The percentage (\%) of reduction of the red coloured ferrozine- $\mathrm{Fe}^{2+}$ complex formation was calculated.

\section{Total phenolic content}

The total phenolic content of foxtail millet ethanolic extracts was determined spectrophotometrically with Folin-Ciocalteu reagent (Yu et al. 2004). The absorbance at $765 \mathrm{~nm}$ was measured. Gallic acid was used as standard. The phenolics content was expressed in gallic acid equivalent per gram of foxtail millets dry weight (mg GAE/g dw).

\section{Total flavonoid content}

The total flavonoid content of foxtail millets was determined spectrophotometrically with aluminium chloride (Kreft et al. 2002). The absorbance at $420 \mathrm{~nm}$ was measured. The amount of total flavonoids was determined using a standard curve prepared of rutin and expressed in rutin equivalent per gram of foxtail millets dry weight (mg rutin/g dw).

\section{Phenolic compound analysis by HPLC/DAD}

HPLC analysis was carried out with Agilent 1200 Series HPLC system equipped with diode array detector and Zorbax Eclipse XDB-C18 column $(4.6 \times 150 \mathrm{~mm}, 5 \mu \mathrm{m}$, Agilent Technologies, Santa Clara, California, USA). Elution was performed using a gradient system. The solvent system consisted of solvent A: water/acetic acid mixture adjusted to $\mathrm{pH} 2.8$, and B: acetonitrile. The flow rate was $1 \mathrm{ml} / \mathrm{min}$ and the detection wavelength was $272 \mathrm{~nm}$ and $350 \mathrm{~nm}$, respectively. Individual phenolic compounds in samples were identified according to the standards of phenolic acids and flavonoids. The phenolics quantification was evaluated with ChemStation software 12.2.

\section{Statistical analysis}

Analyses were performed in triplicates for proximate evaluations and in quadruplicates for other methods. Obtained data were reported as means \pm standard deviation. Results were subjected to correlation analysis and analysis of differences among mean values by Student test. Statistical significance was declared at $p<0.05$. 


\section{Results}

\section{Proximate composition}

The results of content of primary nutrients, including protein, fat and soluble sugars of foxtail millet genotypes are presented in Table 1. Different compositions were determined depending on the millet genotype. Yellow genotype Slovenský had the highest content of fat and proteins, but the least soluble sugars level. In contrary, yellow genotype Friderica had the least proteins content and the highest soluble sugars level. The mean values of evaluated parameters were $14.21 \%$ of protein (14.45\% red and $13.97 \%$ yellow genotype), $5.03 \%$ of fat (4.65\% red and $5.42 \%$ yellow genotype) and $4.28 \%$ of soluble sugars $(4.31 \%$ red and $4.25 \%$ yellow genotype).

Table 1. Proximate composition of foxtail millet genotypes

\begin{tabular}{|l|c|c|c|}
\hline \multicolumn{1}{|c|}{ Foxtail millet } & Protein (\%) & Fat (\%) & Soluble sugars (\%) \\
\hline Red genotype & $14.58 \pm 0.14^{\mathrm{a}}$ & $4.45 \pm 0.02^{\mathrm{a}}$ & $4.54 \pm 0.01^{\mathrm{a}}$ \\
\hline 00002 & $14.33 \pm 0.14^{\mathrm{a}}$ & $4.86 \pm 0.07^{\mathrm{b}}$ & $4.09 \pm 0.04^{\mathrm{b}}$ \\
\hline 0011 & $15.32 \pm 0.01^{\mathrm{b}}$ & $6.06 \pm 0.08^{\mathrm{c}}$ & $3.54 \pm 0.01^{\mathrm{c}}$ \\
\hline Yellow genotype & $12.72 \pm 0.13^{\mathrm{c}}$ & $4.78 \pm 0.03^{\mathrm{b}}$ & $4.96 \pm 0.01^{\mathrm{d}}$ \\
\hline Slovenský & $8.9 \pm 0.00$ & $5.7 \pm 0.04$ & $6.5 \pm 0.29$ \\
\hline Friderica & $13.32 \pm 0.62$ & $2.69 \pm 0.54$ & $4.71 \pm 0.72$ \\
\hline Proso millet (Panicum miliaceum) & \\
\hline Wheat (Triticum aestivum)** &
\end{tabular}

${ }^{\mathrm{a}-\mathrm{d}}$ Values in column followed by different letters are significantly different $(p<0.05)$.

*Value of genotype Unikum (unpublished data).

**Mean value of 7 genotypes (Mikulajová et al. 2008).

\section{Lipids profile}

Obtained data of foxtail millet fatty acids composition are presented in Table 2. Considerable variance in lipids profile among foxtail millet genotypes was not observed. About $87 \%$ of lipids in the foxtail millet genotypes were unsaturated. Linoleic acid (66-70\%) was the dominant unsaturated fatty acid, followed by oleic (14-16\%) and linolenic (2-3\%) acids. The high linoleic n-6/linolenic $n-3$ ratio $(20 / 1-32 / 1)$ was recorded. The main saturated fatty acid was palmitic acid (7-10\%).

\section{Antioxidant properties}

Antioxidant properties of foxtail millet genotypes were investigated with three independent in vitro methods - DPPH radical scavenging activity, $\beta$-carotene/linoleic acid bleaching method and chelating activity on $\mathrm{Fe}^{2+}$, based on different reaction mechanism. The 
Table 2. Fatty acid composition of foxtail millet genotypes

\begin{tabular}{|c|c|c|c|c|c|}
\hline \multirow{2}{*}{ Fatty acids $(\%)$} & \multicolumn{2}{|c|}{ Red genotype } & \multicolumn{2}{|c|}{ Yellow genotype } & \multirow{2}{*}{$\mathrm{CV}$} \\
\hline & 00002 & 0011 & Slovenský & Friderica & \\
\hline Caprylic acid (C 8:0) & nd & 0.08 & 0.20 & 0.10 & - \\
\hline Myristic acid (C 14:0) & 0.07 & 0.05 & nd & 0.07 & - \\
\hline Pentadecylic acid (C 15:0) & 0.08 & 0.05 & nd & 0.08 & - \\
\hline Palmitic (C 16:0) & 9.39 & 7.48 & 7.94 & 10.07 & 16.24 \\
\hline Palmitoleic (C 16:1-9c) & 0.12 & 0.15 & 0.22 & 0.16 & 23.73 \\
\hline Margaric acid (C 17:0) & 0.10 & 0.10 & 0.13 & 0.15 & 20.02 \\
\hline Stearic (C 18:0) & 1.39 & 1.29 & 1.69 & 2.94 & 43.53 \\
\hline Oleic (C 18:1-9c, n-9) & 14.55 & 16.37 & 14.78 & 14.36 & 7.01 \\
\hline Elaidic (C 18:1-9t) & nd & nd & 0.10 & nd & - \\
\hline Vaccenic (C 18:1-11c) & 0.84 & 0.521 & 0.76 & 0.713 & 20.79 \\
\hline $\begin{array}{l}\text { Linoleic } \\
\text { (C 18:2-9c,12c, n-6) }\end{array}$ & 68.33 & 69.64 & 68.75 & 65.65 & 3.08 \\
\hline $\begin{array}{l}\text { Conjugated linoleic } \\
\text { (C 18:2-t9,t11, n-6) }\end{array}$ & nd & 0.17 & 0.55 & 0.20 & - \\
\hline $\begin{array}{l}\alpha \text {-Linolenic } \\
(\mathrm{C} 18: 3-9,12,15 \mathrm{c}, \mathrm{n}-3)\end{array}$ & 2.39 & 2.30 & 2.15 & 3.29 & 23.97 \\
\hline Arachidic (C 20:0) & 0.62 & nd & 0.70 & nd & - \\
\hline Eicosenoic (C 20:1-11c) & 0.47 & 0.41 & 0.43 & 0.39 & 5.09 \\
\hline $\begin{array}{l}\text { Eicosadienoic acid } \\
(\mathrm{C} 20: 2-11 \mathrm{c}, 14 \mathrm{c}, \mathrm{n}-6)\end{array}$ & 0.08 & 0.07 & & & - \\
\hline Heneicosylic (C 21:0) & 0.08 & nd & nd & 0.09 & - \\
\hline Behenic (C 22:0) & 0.90 & 0.78 & 1.08 & 0.91 & 26.39 \\
\hline Tricosylic (C 23:0) & 0.13 & 0.09 & nd & 0.12 & 16.19 \\
\hline Lignoceric (C 24:0) & 0.31 & 0.28 & 0.26 & 0.35 & 16.09 \\
\hline IU & 1.60 & 1.60 & 1.64 & 1.57 & \\
\hline$n-6: n-3$ ratio & 28.6 & 30.3 & 31.9 & 19.9 & \\
\hline
\end{tabular}

$\mathrm{IU}$ - index of unsaturation; CV - variation coefficient; nd - not detected.

first two methods are based on assessment of antioxidant ability to scavenge stable radicals and also radicals generated during oxidation process, respectively. The third method measures metal chelating ability of antioxidants. The application of several methods allows to cover different aspects of antioxidant efficacy. Evaluation of antioxidant activity may be more reliable in this way. 


\section{DPPH radical scavenging activity}

DPPH methods are not specific for individual antioxidant compounds but they provide information about total antioxidant capacity of sample. DPPH radical is a stable, nitrogen centred free radical with an unpaired electron that is converted to a stable diamagnetic molecule in the presence of a hydrogen or electron donating antioxidant (Rajesh and Natvar 2011). DPPH radical scavenging activity of tested foxtail millet genotypes ranged from 0.56 to $1.26 \mathrm{mg} \mathrm{DPPH} / \mathrm{g} \mathrm{dw}$ (Table 3). Differences in obtained values were statistically significant $(p<0.05)$. Red foxtail millet genotype 00002 showed the highest antioxidant activity, on the contrary to the yellow genotype Friderica with the lowest activity. If the results were expressed in percentages of scavenged radicals, then the red genotypes 00002, 0011 and the yellow genotypes Slovenský, Frederica scavenged 44\%, 33\% and $39 \%, 20 \%$ of the DPPH radicals, respectively. The red genotypes scavenged $1.10 \mathrm{mg}$ $\mathrm{DPPH} / \mathrm{g} \mathrm{dw}$ and the yellow one $0.84 \mathrm{mg} \mathrm{DPPH} / \mathrm{g} \mathrm{dw}$, on average.

Table 3. Antioxidant activity of foxtail millet genotypes

\begin{tabular}{|l|c|c|c|}
\hline \multicolumn{1}{|c|}{ Foxtail millet } & $\begin{array}{c}\text { DPPH radical scavenging } \\
\text { activity } \\
\text { (mg DPPH/g dw) }\end{array}$ & $\begin{array}{c}\beta \text {-Carotene/linoleic acid } \\
\text { bleaching method (\%) }\end{array}$ & $\begin{array}{c}\text { Chelating activity } \\
(\%)\end{array}$ \\
\hline Red genotype & $1.26 \pm 0.05^{\mathrm{a}}$ & $93.17 \pm 0.59^{\mathrm{a}}$ & $2.58 \pm 0.08^{\mathrm{a}}$ \\
\hline 00002 & $0.94 \pm 0.04^{\mathrm{b}}$ & $85.94 \pm 0.96^{\mathrm{b}}$ & $2.52 \pm 0.06^{\mathrm{a}}$ \\
\hline 0011 & & & $2.36 \pm 0.04^{\mathrm{b}}$ \\
\hline Yellow genotype & $1.11 \pm 0.04^{\mathrm{c}}$ & $95.52 \pm 0.22^{\mathrm{c}}$ & $2.82 \pm 0.11^{\mathrm{c}}$ \\
\hline Slovenský & $0.56 \pm 0.01^{\mathrm{d}}$ & $58.30 \pm 1.98^{\mathrm{d}}$ & \\
\hline Friderica &
\end{tabular}

Values in each column having the same superscript are not significantly different $(p>0.05)$.

\section{B-carotene/linoleic acid bleaching method}

In process of linoleic acid oxidation the free radicals are formed. They attack highly unsaturated $\beta$-carotene molecules. This process leads to loss of yellow-orange colour of $\beta$-carotene (Yumrutas and Saygideger 2010). Antioxidants present in samples are able to scavenge linoleic acid radical and thus protects $\beta$-carotene from oxidation. All foxtail millet samples effectively inhibited formation of linoleic acid free radicals and consequently $\beta$-carotene oxidation (Table 3 ). Antiradical activity depended on the foxtail millet genotypes (ranged from 58.3 to $95.5 \%$ ) and was in the descending order: Slovenský $($ yellow $)>00002($ red $)>0011($ red $)>$ Friderica (yellow).

\section{Ferrous ion chelating activity}

Ferrous ions can promote free radical reactions to generate highly destructive reactive oxygen species in biological systems. Chelating compounds can delay this radical gen- 
eration by stabilizing the ions. This process can consequently suppress oxidative damage (Chandrasekara and Shahidi 2012).

The weak ability of foxtail millet samples to chelate ferrous ions was observed (Table 3). The percentage of chelating activity ranged from 2.4 to $2.8 \%$. The differences between samples were statistically significant $(p<0.05)$, except for red genotypes. In contrast to the previous results, the yellow genotype Friderica showed the highest ferrous ion chelating ability, contrariwise, genotype Slovenský showed the lowest level.

\section{Phenolics analysis}

\section{Total phenolic content}

The total content of phenolic compounds in foxtail millet genotypes ranged from 0.38 to $0.55 \mathrm{mg} \mathrm{GAE} / \mathrm{g} \mathrm{dw}$ (Fig. 1). Statistically significant differences between genotypes were found $(p<0.05)$ and they decreased in the order: 00002 (red) $>$ Slovenský (yellow) $>0011$ (red) $>$ Friderica (yellow). The mean phenolics content for the red genotypes was $0.47 \mathrm{mg}$ $\mathrm{GAE} / \mathrm{g} \mathrm{dw}$ and for the yellow one was $0.44 \mathrm{mg} \mathrm{GAE} / \mathrm{g} \mathrm{dw}$.

\section{Total flavonoid content}

Particular genotypes of foxtail millet differed significantly also in the total flavonoid content $(p<0.05)$. The highest content of total flavonoids was shown by red genotypes 00002 $(0.21 \mathrm{mg} \mathrm{rutin} / \mathrm{g} \mathrm{dw})$ and the least by yellow genotypes Friderica $(0.16 \mathrm{mg}$ rutin $/ \mathrm{g} \mathrm{dw})$. Results are given in Fig. 1. The mean value of total flavonoids for the red genotypes was $0.19 \mathrm{mg}$ rutin $/ \mathrm{g} \mathrm{dw}$ and for the yellow genotypes was $0.18 \mathrm{mg} \mathrm{rutin} / \mathrm{g} \mathrm{dw}$.

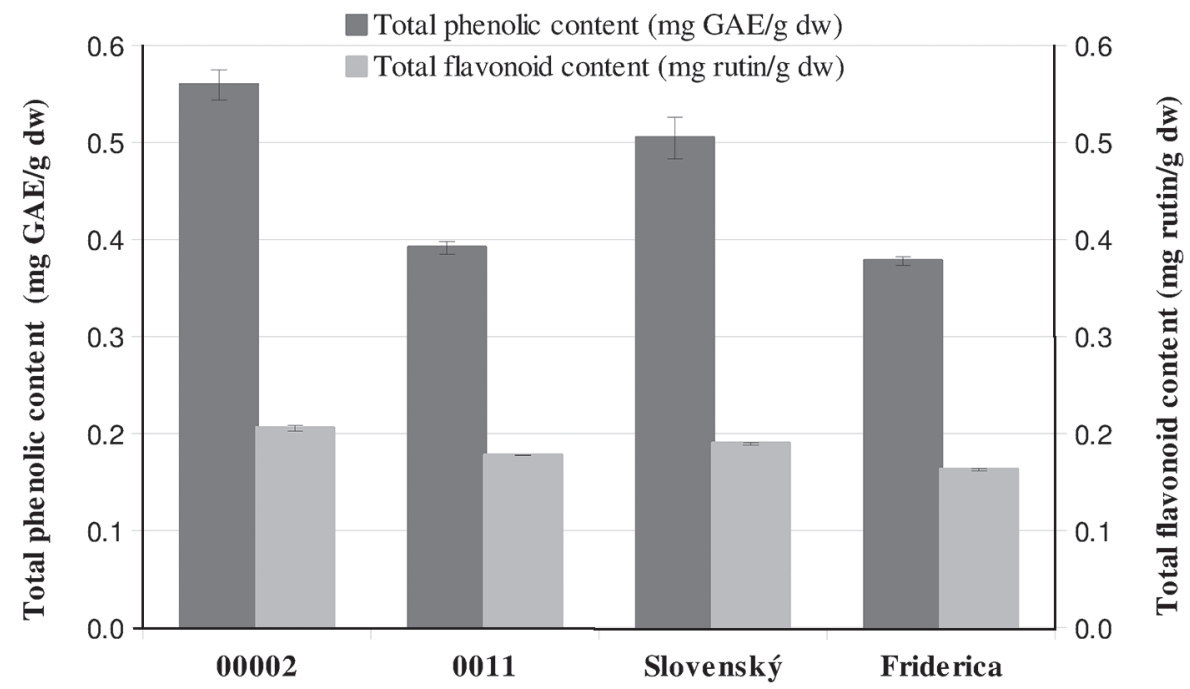

Figure 1. Total phenolic (mg GAE/g dw) and total flavonoid (mg rutin/g dw) content in foxtail millet genotypes 


\section{Identification of phenolic compounds}

Four hydroxybenzoic acids (gallic, protocatechuic, vanillic and syringic acid) and two hydroxycinnamic (ferulic and $p$-coumaric acid) were identified and quantified in foxtail millet genotypes by HPLC-DAD methods (Table 4).

Generally, the level of hydroxycinnamic acids was higher than the level of hydroxybenzoic acids. The content of $p$-coumaric and ferulic acids were dominant in all genotypes and their contribution to the total phenolic content ranged between $52.3-57.4 \%$, and $14.1-18.5 \%$, respectively. Gallic acid was present in the least amount and contributed with only $1.6-2.1 \%$ to the total phenolic acids content. Protocatechuic acid was determined only in the yellow genotype Slovenský. Chandrasekara and Shahidi (2011) identified in the soluble fraction of foxtail millet grain $p$-hydroxybenzoic, gentisic acid, as well. Zhang and Liu (2015) detected ferulic, chlorogenic, caffeic, $p$-coumaric and syringic acid in two foxtail millet genotypes.

Moreover, the presence of flavonoids - rutin and quercetin, was searched, but they were not positively identified. In accordance with the above-mentioned results of the total flavonoid content, the occurrence of other flavonoids is evident. Chandrasekara and Shahidi (2011) identified catechin, quercetin-0-pentoside, apigenin and 6- $C$-glucosyl-8-Carabinosyl apigenin in soluble fraction of foxtail millet grain.

The total content of phenolic acids in tested foxtail millet genotypes as quantified by HPLC decreased as follows: 00002 (red) > Slovenský (yellow) > 0011 (red) > Friderica

Table 4. The results of HPLC/DAD analysis of phenolic acid content $(\mu \mathrm{g} / \mathrm{g} \mathrm{dw})$ in foxtail millet genotypes

\begin{tabular}{|l|c|c|c|c|}
\hline \multirow{2}{*}{$\begin{array}{c}\text { Phenolic acid } \\
(\mu \mathrm{g} / \mathrm{g} \mathrm{dw})\end{array}$} & 00002 & 0011 & \multicolumn{2}{c|}{ Yellow genotype } \\
\cline { 2 - 5 } & $1.51 \pm 0.05^{\mathrm{a}}$ & $1.36 \pm 0.07^{\mathrm{b}}$ & $1.64 \pm 0.05^{\mathrm{c}}$ & $0.84 \pm 0.03^{\mathrm{d}}$ \\
\hline Gallic acid & $\mathrm{nd}$ & $\mathrm{nd}$ & $6.03 \pm 0.01$ & nd \\
\hline Protocatechuic & $14.33 \pm 0.50^{\mathrm{a}}$ & $8.98 \pm 0.04^{\mathrm{b}}$ & $10.46 \pm 0.12^{\mathrm{c}}$ & $5.90 \pm 0.21^{\mathrm{d}}$ \\
\hline Vanillic & $9.83 \pm 0.12^{\mathrm{a}}$ & $8.68 \pm 0.39^{\mathrm{b}}$ & $9.02 \pm 0.81^{\mathrm{abc}}$ & $8.41 \pm 0.02^{\mathrm{bc}}$ \\
\hline Syrigic & $48.68 \pm 0.98^{\mathrm{a}}$ & $43.93 \pm 0.83^{\mathrm{b}}$ & $42.22 \pm 0.80^{\mathrm{c}}$ & $28.29 \pm 1.20^{\mathrm{d}}$ \\
\hline$p$-Coumaric & $16.18 \pm 0.74^{\mathrm{a}}$ & $13.60 \pm 0.50^{\mathrm{b}}$ & $11.40 \pm 0.39^{\mathrm{c}}$ & $9.85 \pm 0.27^{\mathrm{d}}$ \\
\hline Ferulic & 90.53 & 76.55 & 80.77 & 53.29 \\
\hline PHA & 64.86 & 57.54 & 53.62 & 38.13 \\
\hline HCA & 25.67 & 19.01 & 27.15 & 15.15 \\
\hline HBA & 71.64 & 75.16 & 66.38 & 71.56 \\
\hline $\mathrm{P}_{\text {HCA }}(\%)$ & 17.88 & 17.77 & 14.11 & 18.48 \\
\hline $\mathrm{P}_{\text {FA }}(\%)$ & 53.77 & 57.39 & 52.27 & 53.08 \\
\hline $\mathrm{P}_{\text {CUM }}(\%)$ & & & \\
\hline
\end{tabular}

Values in each rown having the same superscript are not significantly different $(p>0.05)$.

PHA - total phenolic acids; HCA - total hydroxycinnamic acids; HBA - total hydroxybenzoic acids; $\mathrm{P}_{\mathrm{HCA}}$ - percentage of hydroxycinnamic acids of total phenolic acids; $\mathrm{P}_{\mathrm{FA}}-$ percentage of ferulic acid of total phenolic acids; $\mathrm{P}_{\mathrm{CUM}}-$ percentage of p-coumaric acid of total phenolic acids; nd - not detected. 
(yellow). Genotype 00002 had also the highest content of individual phenolic acids, except for gallic acid. The highest value of this phenolic acid was assessed in genotype Slovenský. The mean value for the red genotypes was $83.5 \mu \mathrm{g} / \mathrm{g} \mathrm{dw}$ and for the yellow one was $67.1 \mu \mathrm{g} / \mathrm{g} \mathrm{dw}$.

\section{Discussion}

Results obtained in our study showed that foxtail millet is a valuable source of proteins, essential fatty acids and antioxidants. In terms of nutrition, it is interesting to note higher protein content of foxtail millet as compared to proso millet (Panicum miliaceum) and wheat (Triticum aestivum, one of the major produced cereals) (Table 1). Kamara et al. (2009) reported $2.4 \%$ and $2.9 \%$ of fat, and $11.5 \%$ and $11.4 \%$ of protein for white and yellow foxtail millets, respectively, and the results were relatively low compared with our ones. Similar values of fat $(4.8 \%$ and $4.9 \%)$, and lower values of protein $(11.3 \%$ and $13.4 \%$ ) were found by Devisetti et al. (2014) in two genotypes of foxtail millet brown grains.

Lipids represent minor components in cereal grains. However, they are fundamental nutritional factors, and important is their role during processing and storage of cereals and cereal products. Evaluated genotypes of foxtail millet were characterized by a high degree of fatty acids unsaturation (1.57-1.64), which is desirable from nutritional point of view. Both linoleic and linolenic acids are essential fatty acids for humans. The balanced intake of n-6 and n-3 strongly affects the physiological functions, it is important for good health and normal development. The optimal ratio n-6/n-3 fatty acids can be depending on the specific disease (Simopoulos 2002). Generally, western diets are abundant in n-6 fatty acids (n-6/n-3 ratio 14/1 - 20/1) and the need for an increased intake of foods higher in n-3 fatty acids is suggested (Alvarez-Jubete et al. 2010). The ratio of linoleic to linolenic acid in the diet were in FAO/WHO Report (1994) recommended between 5/1 and 10/1. In FAO/WHO Report (2010), the optimal n-6/n-3 ratio is not specified, there is emphasize importance of observance of recommendations on intakes of saturated and unsaturated fatty acids.

Foxtail millet genotypes demonstrated considerable radical scavenging activities. Taking all measured data into consideration, it can be concluded that foxtail millet contains substances predominantly active as primary, chain-breaking antioxidants able to donate hydrogen atoms, and there were less secondary antioxidant components. There was a good correlation between the methods for measuring free radical scavenging antioxidant function, namely DPPH vs. $\beta$-carotene bleaching, $\mathrm{R}=0.953$, what suggest that these methods have similar predictive capacity for foxtail millets antioxidant activities. The indirect relationship was found between the chelating activity and the radical scavenging methods $(\mathrm{R}=-0.742, \mathrm{R}=-0.905)$.

The order in total phenolic content was the same as in the total flavonoid content and DPPH radical scavenging capacity, which denotes significant relationship between the mentioned parameters. Correlation coefficient between the total phenolics and DPPH methods, and the total flavonoids and DPPH methods was $\mathrm{R}=0.887$ and $\mathrm{R}=0.970$, re- 
spectively (Table $\mathrm{S} 1^{*}$ ). These results indicate that the predominant source of the antioxidant activity derives from the phenolic compounds, including flavonoids. However, antioxidant activity of non-phenolic compounds (for example tocopherols, carotenoids, $\beta$-glucan), synergistic action of individual compounds and diverse contribution of individual constituents to overall antioxidant behaviour should be also taken into account. That suggested the results of $\beta$-carotene/linoleic acid bleaching method, in which genotype with lesser phenolics and flavonoids amount showed higher ability to scavenge the linoleic acid free radicals. The antioxidant activity of a substance can vary among methods depending on factors such as antioxidant solubility, oxidation state, medium $\mathrm{pH}$ and type of substrate (Alvarez-Jubete et al. 2010).

Phenolic compounds are known for their many biological activities, including antioxidant, antitumour, anti-inflammatory and antimicrobial effects (Heleno et al. 2015). For understanding of antioxidant behaviour of foxtail millet, it is important to know not only total phenolic content, but also the phenolic profile. The antioxidant efficacy of phenolics is diverse and depends on many factors, such as the number of hydroxyl groups bonded to the aromatic ring, the site of bonding and mutual position of hydroxyls in the aromatic ring, character of other substituent and their position in relation to the hydroxyl groups (Mathew et al. 2015). In our study, the red genotype 0011 has higher content of $p$-coumaric and ferulic acid-cinnamic acid derivatives in comparison to the yellow genotype Slovenský, but the lower antioxidant activity. This can be attributed to the presence of protocatechuic acid and higher gallic acid content in genotype Slovenský. Protocatechuic acid is a better antioxidant than ferulic or $p$-coumaric acid, respectively.

Correlation analysis between individual phenolic acids and antioxidant activity methods were also determined. Results are presented in Table S1. High correlations were found between the antioxidant activities evaluated by the DPPH and $\beta$-carotene/linoleic acid bleaching methods and the total phenolic acid content, as well as identified phenolic acids, mainly gallic and $p$-coumaric acids. Negative correlations were found between phenolic acids content and chelating activity.

The foxtail millet grain colour relates with phenolic compounds amount or radical scavenging capacity, respectively, we cannot specifically infer. It would be necessary to evaluate more genotypes to get more exact conclusion. However, we observed relation to intensity of grain colour. The more intensely red and yellow grains (i.e. darker red 00002 and yellow Slovenský genotypes), respectively, showed better properties. To the best of our knowledge, such relation has not been published before.

The deviations in the biosynthesis stabilities of the compounds studied are also discussed. The variation coefficients were calculated. Quite low variation coefficient was observed with oleic, linoleic and eicosenoic acid (Table 2), and with the total flavonoids and syringic acid (Table S1). Variation coefficients characterise the variability of the data set studied, according to them we are able to conclude, whether the genetic factors lead to different levels of individual component creation. Low variation coefficient indicates high degree of biosynthesis stability of crops component. Apart from the genetic factors, the environmental factors, such as nutrients and water availability, as well as weather and

*Further details about the Electronic Supplementary Material (ESM) can be found at the end of the article. 
further growing conditions may play important roles in the biosynthesis of secondary metabolites, including phenolics.

This study was designed to determine and compare the basic nutritive components protein, fat, soluble sugars; bioactive components - fatty acids, the total phenolics, the total flavonoids and individual phenolic acids in four foxtail millet genotypes. Foxtail millet possesses high content of protein, fat, essential fatty acids. About $87 \%$ of the lipids are unsaturated. Foxtail millet is a good source of antioxidants and has good radical scavenging activity. Contribution of phenolic compounds to the antioxidant function of tested grains was also evaluated and significantly positive and strong correlation was observed between the total phenolic acids and flavonoids and antiradical effects, respectively. Compounds possessing antioxidant activity have beneficial health effects, as well as improve oxidation stability of foods during processing and storing. Selected evaluated parameters were genotype dependent. Presented data may provide supplementing information for classification of foxtail millet genotypes, for transfer and realisation of knowledge in agricultural practice in order to cultivate crops and produce foods with advanced nutritional and antioxidant properties. It may eventuate in better quality and safety of products and human health.

\section{Acknowledgements}

This work was supported by the Agency of the Ministry of Education, Science, Research and Sport of the Slovak Republic for the Structural Funds of EU ITMS 26240220040, Projects Vega 1/0980/15 and VEGA 1/0574/15 and by grant APVV-14-0397 from the Slovak Research and Development Agency, Slovak Republic. The authors thank to Research Institute of Plant Production Piešt'any for providing the seeds for this research project.

\section{References}

Alvarez-Jubete, L., Arendt, E.K., Gallagher, E. 2010. Nutritive value of pseudocereals and their increasing use as functional gluten-free ingredients. Trends Food Sci. Tech. 21:106-113.

Amadou, I., Le, G.W., Amza, T., Sun, J., Shi, Y.H. 2013. Purification and characterization of foxtail milletderived peptides with antioxidant and antimicrobial activities. Food Res. Int. 51:422-428.

Chandrasekara, A., Shahidi, F. 2011. Determination of antioxidant activity in free and hydrolyzed fractions of millet grains and characterization of their phenolic profiles by HPLC-DAD-ESI-MS ${ }^{\mathrm{n}}$. J. Funct. Foods 3:144-158.

Chandrasekara, A., Naczk, M., Shahidi, F. 2012. Effect of processing on the antioxidant activity of millet grains. Food Chem. 133:1-9.

Chlopicka, J., Pasko, P., Gorinstein, S., Jedryas, A., Zagrodzki, P. 2012. Total phenolic and total flavonoid content, antioxidant activity and sensory evaluation of pseudocereal breads. LWT - Food Sci. Technol. 46:548-555.

Čertík, M., Andráši, P., Šajbidor, J. 1996. Effect of extraction methods on lipid yield and fatty acid composition of lipid classes containing gama-linolenic acid extracted from fungi. J. Am. Oil Chem. Soc. 73:357-365.

Čertík, M., Shimizu, S. 2000. Kinetic analysis of oil biosynthesis by arachidonic acid-producing fungus, Mortierella alpina 1S-4. Appl. Microbiol. Biotechnol. 54:224-230. 
Devisetti, R., Yadahally, S.N., Bhattacharya, S. 2014. Nutrients and antinutrients in foxtail and proso millet milled fractions: Evaluation of their flour functionality. LWT - Food Sci. Technol. 59:889-895.

FAO 1994. Food and Nutrition Paper No. 57. Fats and oils in human nutrition: Report of a joint expert consultation. Food and Agriculture Organization of the United Nations. Rome, Italy.

FAO 2010. Food and Nutrition Paper No. 91. Fats and fatty acids in human nutrition: Report of an expert consultation. Food and Agriculture Organization of the United Nations. Rome, Italy.

Gülçın, İ., Oktay, M., Kıreçcı, E., Küfrevıŏlu, Ö.İ. 2003. Screening of antioxidant and antimicrobial activities of anise (Pimpinella anisum L.) seed extracts. Food Chem. 83:371-382.

Hegde, P.S., Chandra, T.S. 2005. ESR spectroscopic study reveals higher free radical quenching potential in kodo millet (Paspalum scrobiculatum) compared to other millets. Food Chem. 92:177-182.

Heleno, S.A., Martins, A., Queiroz, M.J.R.P., Ferreira, I.C.F.R. 2015. Bioactivity of phenolic acids: Metabolites versus parent compounds: A review. Food Chem. 173:501-513.

Ismail, A., Marjan, Z.M., Foong, C.W. 2004. Total antioxidant activity and phenolic content in selected vegetables. Food Chem. 87:581-586.

ISO 11085:2008. Cereals and cereal products - Determination of total fat content. International Organization for Standardization. Geneva, Switzerland.

ISO 20483:2006. Cereals and pulses - Determination of the nitrogen content and calculation of the crude protein content - Kjeldahl method. International Organization for Standardization. Geneva, Switzerland.

ISO 712:2009. Cereals and cereal products - Determination of moisture content - Reference method. International Organization for Standardization. Geneva, Switzerland.

Kamara, T.K., Zhu, K., Amadou, A., Tarawalie, T., Zhou, H. 2009. Functionality, in vitro digestibility and physicochemical properties of two varieties of defatted foxtail millet protein concentrates. Int. J. Mol. Sci. 10:5224-5238.

Kreft, S., Štrukelj, B., Gaberščik, A., Kreft, I. 2002. Rutin in buckwheat herbs grown at different UV-B radiation levels: comparison of two UV spectrophotometric and an HPLC method. J. Exp. Bot. 53:1801-1804.

Makris, D.P., Rossiter, J.T. 2001. Domestic processing of onion bulbs (Allium cepa) and asparagus spears (Asparagus officinalis): effect on flavonol content and antioxidant status. J. Agric. Food Chem. 49:32163222 .

Mathew, S., Abraham, T.E., Zakaria, Z.A. 2015. Reactivity of phenolic compounds towards free radicals under in vitro conditions. J. Food Sci. Technol. 52:5790-5798.

Mikulajová, A., Takácsová, M., Alexy, P., Brindzová, L. 2007. Optimalization of extraction of phenolic compounds from buckwheat on the basis of results of experimental design method. Chem. Listy 101:563-568. (in Slovakian)

Mikulajová, A., Hybenová, E., Gereková, P., Németh, K., Vojteková, S., Kokindová, M. 2008. Presence of selected components in wheat genotypes. Book of Contributions of the XVII. Int. Conf.: Analytical Methods and Human Health. Nový Smokovec, Slovakia, pp. 6-9.

Rajesh, P.M., Natvar, P.J. 2011. In vitro antioxidant activity of coumarin compounds by DPPH, super oxide and nitric oxide free radical scavenging methods. J. Adv. Pharm. Edu. Res. 1:52-68.

Simopoulos, A.P. 2002. The importance of the ratio of omega-6/omega-3 essential fatty acids. Biomed. Pharmacother. 56:365-379.

STN 56 0512:1973. Testing of flour-milling products made of wheat and rye. Slovak Standards Institute. Bratislava, Slovakia.

Yen, G.Ch., Chen, H.Y. 1995. Antioxidant activity of various tea extracts in relation to their mutagenicity. J. Agric. Food. Chem. 43:27-32.

Yu, L., Haley, S., Perret, J., Harris, M. 2004. Comparison of wheat flours grown at different locations for their antioxidant properties. Food Chem. 86:11-16.

Yumrutas, O., Saygideger, S.D. 2010. Determination of in vitro antioxidant activities of different extracts of Marrubium parviflorum Fish et Mey. and Lamiumam plexicaule L. from south east of Turkey. J. Med. Plants Res. 4:2164-2172.

Zhang, L.Z., Liu, R.H. 2015. Phenolic and carotenoid profiles and antiproliferative activity of foxtail millet. Food Chem. 174:495-501. 


\section{Electronic Supplementary Material (ESM)}

Electronic Supplementary Material (ESM) associated with this article can be found at the website of CRC at http://www.akademiai.com/content/120427/

Electronic Supplementary Table S1. Correlation coefficients between phenolic composition and antioxidant activity methods, and variation coefficients calculated for phenolic composition in foxtail millets 